\title{
Éva Izsák
}

\author{
URBAN "SPACE-TWISTS" \\ NEW CHALLENGES OF URBAN GEOGRAPHY
}

\begin{abstract}
In our days, the foremost scene of human life is the city. The history of the last two centuries is also the history of modern cities. At the age of Napoleon, $20 \%$ of the population lived in cities, today this ratio is above $50 \%$. Every second human on Earth lives in a city. Possibly, the most significant transformation of the 21 th Century is related to the growth of cities.
\end{abstract}

"A city is a world that man builds for himself" - wrote Wolf Schneider in 1973, in his book $^{1}$, which is about a historical journey with imaginary wanderings in the cities of past ages. The question presents itself: what does modern man build in its cities? Where do they feel good? What do they use their present spaces for? And what do they do with the artificial environment of the previous system/systems, with these modern urban "scars"?

The structural characteristics of the development, transformation of the cities can be observed in the micro-level transformations of settlements. The change of urban environment is attached to the transformation of both natural and social environment. Peter Hall described the 21st Century habitus of cities as the structure of computers. In his opinion, the physical structure of the cities is the hardware, while the social contexture is the software (HALL P. 2000). These two shape and construct the characteristics of urban space. This expressive metaphor - among others - also marks the relationship between urban society and urban space. In my study I examine the relationship of space and society in the cities, emphasizing the urban space transformations of our days, and at the same time the main characteristics of the social use of urban space. The analysis follows the methodological explanation of the city.

\section{CONCEPTUAL, METHODOLOGICAL INTRODUCTION}

\section{What is the city?}

At the beginning of my study, I would like to clear two conceptual and methodological issues. One of these is the fundamental and regularly occurring question what do we call a city? What is a city? The difficulty of the content and meaning of this often and diversely defined concept is confirmed by the fact that several branches of science tried to create their own definitions of a city. All of these examined human 
settlements from different perspectives, creating their own system of concepts and ways of statistic analysis, in order to investigate the cities. The fact, that every discipline dealing with cities performed their own absolutist examinations can be considered as a deficiency of the often unilateral-looking dissections. Holistic, systematic approach thinking was underdeveloped.

According to the set of ideas of this study, a city cannot be defined from only one point of view. A city is an essential unit of this world which has locality, and attributes related to it ${ }^{2}$. These characteristics inseparably interlock, belonging to the settlement. These are its essential, determinative elements. These are characterized by quantitative and qualitative data. Although their research, analysis is the responsibility of certain disciplines, one simple discipline is not enough for them altogether. Thus the city is such an entity, whose examination can only be carried out in a holistic, transdisciplinary manner. If we accept this, we can understand, that it is hard to compare two independent entities, and the development, change, transformation of two cities ${ }^{3}$. Thus, according to this, a city is such a basic element, which cannot be split into further basic elements of similar nature.

The city as an entity can be classified into classes or layers. The relations of the various layers ${ }^{4}$ compose the hierarchy, creating a network, in which the individual entities (cities) are located, thus forming the unity (a network of cities). This network of cities provides the security of both the system of relations and the neighbourhood, on global, continental, regional and national levels. By and large, this study investigates the city as an entity, namely, the emphasis is on the existence of something (in our case, of the city), and not on finding out the subject of existence, namely, what the city is.

The other, methodological basic idea of the study is not putting the focus of analysis on the space-organizing functions of the city or their systematics. It rather focuses on the transformations, changes within the existing city, accepting that a part of a city mostly consists of the value-bargain ${ }^{5}$ of its inhabitants, the surrounding population, or the mobile communities, thus consisting of social integration. At the same time we must not forget that the communal or public scenes of cities or city-parts are dynamically-changing elements of society. $\mathrm{H}$. Lefebvre defined in $1972^{6}$ that space is a historically created reality, and as such, the use, meaning and determinative symbolism of spaces has importance in every age and every social, political system. Thus, through this we can introduce the everyday life, the transformation processes of the given city, or we can analyse the past as a reality still existing in spaces or premises ${ }^{7}$.

\section{THE "TWISTS" OF CITY RESEARCH AT THE TURN OF THE MILLENNIUM}

In the second part of 20th Century, such significant social-economic changes took place, which not only had an effect on the "spiritual spaces" of the globalized world, but also on the values, geographical approach, socio-physical, socio-cultural relationships 
of urban inhabitants. In the work entitled Postmodern Geographies ${ }^{8}$ published by E. Soja in 1989, it clearly shows, what kind of significant changes passed off in society and in its spiritual directives from the middle of the 1960's. The "spatiality" of society has changed. The limits of the previous, static immobility, the frameworks of living space became "globalized". All of this had an effect not only on the economic and political processes of society, but also on their conception of spaces, and on the research concerning them. An obvious "scene" of this became incorporated in the city", containing a constantly growing number of population ${ }^{10}$ globally.

The thorough and modernistic qualitative examination of the processes running in the city has started and spread around in the scientific sphere after the publication of two works, which essentially reshaped city geography too. The work entitled Thirdspace ${ }^{11}$ draw attention to the importance of experienced space, which tries to interpret and examine subjective spaces composed of an individual or individuals, groups. The understanding of the processes and the social background draw the attention of researchers to such new issues, as for example the readings of urban spaces, the importance of composing, creating a space ${ }^{12}$, or the forms and practices of the occupation of spaces ${ }^{13}$. Upon the publication of Soja's work, these processes, already analysed in historic science, cultural anthropology, sociology, received their new meaning in city geography too.

E. Soja's work, entitled Postmetropolis ${ }^{14}$ was published in 2000 , in which he already wrote about the city-geographic processes, space transformations, and the sociophysical phenomenon characterizing the cities of the globalized world. Thus, according to Soya, the characteristics suitable and necessary for further investigation are as follows:

- Fleyicity - strong functional and spatial fragmentation, typical to a postindustrial city

- Cosmopolis - a cultural and economic primacy of globalisation

- Exopolis - the traditional city becomes "permuted", the downtown and the surrounding areas are functionally transformed too.

- Metropolarities - growing number of social inequalities, polarisation, conflicts and their habitus in the texture of the city

- "carcareal archipelagoes" - continuous observation, guarding and control of the city areas

- Hybridisation (simcity) - coexistence of reality and geographical imagination

The urban space-transformations, postmodern society and the process of globalisation has not only changed the urbanisation processes in North America and Western Europe. From the beginning of the 90's, spectacular transformations have taken place in the cities of post-socialist countries, thus in Budapest too. 


\section{CITY - CITY GEOGRAPHY - POSTMODERN SOCIETY}

Upon accepting the city as an entity, the question presents itself: what responsibilities does a geographer have in this entity? In my introduction I have already pointed out the located nature of the city and the importance of the attributes related to location. The located nature of the city marks the geographical location where the city is formed and developed. The transformation and use of natural space is the first step. It is followed by the correlations between geographical capabilities as attributes, and society as occupying force, with the resultant being the city itself. The geographical appearance of the city is defined by the filling and usage of spaces ${ }^{15}$.

Post-modern society, globalized economy and the changes in the relation of space and time has transformed the geographical appearance of the cities too. Spaceorganizing forces have changed, the interpretation of place, geographical location have also been transformed. Urban spaces have history, relativity, identity ${ }^{16}$. These compose - among others - the geographical image of the city. Post-modern era pursues physical modifications. It transforms the inner sphere of cities, the number of places without identity, the so called "no-spaces" is increasing, the typical zones, areas of post-modern cities are formed. The inner structure of the city changes, the city is shaped by new elements. Previous regularity has been changed to irregularity. The new, previously non-existing forms of space occupation could even be extraneous for certain urban social groups. In the city of today, fragmented - previously more uniform - structure and concentrated, function-compressing space occupation are present at the same time. Thus - for example in Budapest too - the previously uniform city structure has fallen into pieces. The changed social, political, economic relations have fragmented the functional city areas. It is hard to make a distinction between purely living or working districts. Beyond this, mega shopping centres have appeared with enormous area, where several urban functions appear in a concentrated form. Space - function - social relations have basically changed in the cities.

The cities, being individual entities, respond to these changes in their own unique way. The transformation of the geographical image of North-American, WesternEuropean, Post-Socialistic cities are all different, just as the change of the spaceorganizing force of these cities. Beyond the obvious differences, there are serious environment-psychical, city-sociological, architectural disparities too. For the collective effect of all these, the identity of the spaces and places of the city changes too. Besides this, the natural image ${ }^{18}$ of the city can also change and be transformed. As landscape is an inside element of the city, and although city-sized nature is of smaller scale, still a part and important element of urban research is the investigation of the changes and transformations of natural geography. It is especially true in cities like Budapest, where natural environment and its inner-city attributes played such an important role, and they still do as of today. Thus, this study aims to point out the space-transformations, space-changes which determine the citygeographical space twists of Budapest. 


\section{CHARACTERISTICS OF THE "NEW" URBAN WORLD}

Post-modern society, globalized economy, the changes in the relation of space and time has changed the world of cities, the meaning and significance of their inner spaces, as well as the inhabitants' use of space. "New" urban world has basically gone through a two-fold transformation. The hierarchy of the cities has changed, just as the factors of the city-competition, which is the successfulness of the city.

Settlements, including the cities arrange into a hierarchic structure, and thus they compose the totality of the stock of settlements, the settlement network. Previous regional examinations analysed the hierarchy of settlements on regional, national, international, or maybe on continental level, as the functional sub- and superordinance relations (concerning both economic and political functions) could only be determined on these regional levels. International comparison, global-scale collating of the cities was incomprehensible ${ }^{19}$. Due to the effect of globalization, city-hierarchy has changed, municipal sub- and super-ordinance relations has been "rearranged". As a result of global transformations, such "supercities", globalized municipalities could emerge on the top of the hierarchy, which became determinative on specific areas of life. Saskia Sassen defined global cities in $1991^{20}$, as decisive and innovative centres determining the new patterns of city-competition ${ }^{21}$.

Competition of cities is constant. Amongst the constantly changing world-economic relationships newer and newer factors are necessary to keep up the persistent success of a city. As global cities are also seriously affected by the setbacks following economic growth, new "success-factors" were needed in order to partake in city-competition. Following the few-decades-old history of knowledge-based economy, in the 1990's, and then at the millennium, a new expression - the idea of creative economy - has appeared. Creativity started to appear as the basic value of selection. Following the explanations of natural sciences ${ }^{22}$, it received more and more attention outside of business life too. The perception of systematic approach has become more and more prevalent, in which cultural medium, and the significance of social sphere became a factor of creativity besides individual performance. Namely, the prevailing trends, traditions and the creations comprehended by society as well as the social medium accepting or even denying these (for example Csíkszentmihályi) ${ }^{23}$. Thus, the process of creativity is a result of the interactions of the individual, the cultural medium and the social field. So, creativity is a social phenomenon, having no objective criteria.

This way, creativity, appearing as a success-factor of cities creates an economy, where knowledge is perceived as a useful activity creating new formulas, namely, creative industries are born, composing a creative economy. At those municipalities, cities, where the coefficients of creative economy are present concentrated, the creative class operating the whole process is more and more firm and successful in the social field which creates and supports these factors. Thus, creative class is an essential success-factor for the "emergence" of cities (Florida $2002^{24}$, Florida, $2005^{25}$ ) 


\section{URBAN "SPACE-TWISTS"}

The constant increase of the number of urban population, social, economic transformations are obviously present in the sphere where all of these happen. Namely, the transformation of urban space signifies that the "imprints" of dynamic urban life are present in every municipality, in every city.

\section{NOTES}

1. Wolf Schneider (1973): Cities from Ur to Utopia. Gondolat, Budapest

2. It especially emphasises the raison d'etre of city-geographics even amongst those examining the city as an individual discipline

3. A. András Gergely (2006, 2010): City in the Picture.

4. pl. Camagni, p.: Nested hierarcie

5. A.András Gergely i.m. p.4.

6. Henri Lefebvre (1972): Creation of space

7. M. de Certeau (1980): About the Practices of Everyday Life

8. Edward Soja (1989): Postmodern Geographies: The Reassertion of Spaces in Critical Social Theory. London, Verso Press

9. Scott, A.J. and E.W.Soja eds. (1996): The City: Los Angeles and Urban Theory at the End of the Twentieth Century. Berkeley, University of California Press,

10. according to UN estimations, (2007) the number of urban inhabitants on Earth increases with 170000 weekly. In 2008 - first time in history - there are more people living in cities than in villages on Earth

11. Edward W. Soja (1996): Thirdspace. Journey's to Los Angeles and Other Real-and-Imagined Plces. Blackwell Publishers.

12. Henri Lefebvre (1971): The Production of Space

13. Michel de Certeau (1980): The Practice of Everyday Life

14. Edward W. Soja (2000): Postmetropolis. Critical Studies of Cities and Regions. Blackwell Publishers.

15. György Enyedi (2012): Urban World Akadémiai kiadó, Budapest. p.26.

16. Marc Augé (2012): Nicht-Orte. Verelag C.H. Beck. +. Auflage. p.83.

17. Marc Augé im: pp.:79-80.

18. György Enyedi im.: pp. 37-38

19. The concept of cosmopolis was first formulated by Sir Patrick Geddes in his work entitled "Cities in Evolution"

20. Sassen, Saskia (1991) : The global city. new York, London, Tokyo. Princeton University Press. Princeton and Oxford. pp.:23-36

21. at the beginning of the 90 's, S.Sassen set apart three global cities: London, New York and Tokyo

22. mostly approached from biology, medical science and psychology

23. Mihály Csíkszentmihályi (1997) Flow. Budapest.

24. Richard Florida (2002) The Rise of the Creatív Class.. Basic books. New York. pp.:35-64

25. Richard Florida (2005): Cities and the creatív class.. Routledge, New York-London. pp.:27-48. 